\title{
Research Paper: Investigating the Prevalence of Peripheral Neuropathy in Chemical Burns
}

\author{
Ladan Masoumi $^{1}$ (D), Seyed Ehsan Daneshmand ${ }^{2 *}$ (D), Sharareh Roshanzamir ${ }^{3}$ (D) \\ 1. Department of Physical Medicine and Rehabilitation School of Medicine, Shiraz University of Medical Science, Shiraz, Iran. \\ 2. Orthopaedic Residency Bone and Joint Reconstruction Research Center, Iran University of Medical Sciences, Tehran, Iran. \\ 3. Associate Professor of Physical Medicine and Rehabilitation, School of Medicine, Shiraz University of Medical Sciences, Shiraz, Iran
}

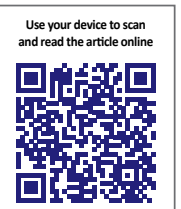

Citation Masoumi L, Daneshmand SE, Roshanzamir S. Investigating the Prevalence of Peripheral Neuropathy in Chemical Burns. Journal of Research in Orthopedic Science. 2021; 8(1):23-28. http://dx.doi.org/10.32598/JROSJ.8.1.742.1

: http://dx.doi.org/10.32598/JROSJ.8.1.742.1

(c) (1) (5)

Article info:

Received: 22 Sep 2020

Revised: 10 Oct 2020

Accepted: 04 Jan 2021

Available Online: 01 February 2021

Keywords:

Prevalence of peripheral neuropathy, Chemical burns, Peripheral nerve

\begin{abstract}
A B S T R A C T
Background: With the growing number and variety of chemical agents used in industry and for home purposes, chemical burns and their consequences have drawn physicians' attention. Involvement of the nervous system that is a major consequence of systemic chemical exposure can be problematic in local chemical burns, as well. This study was designed to evaluate the peripheral nervous system in chemical burn victims.
\end{abstract}

Objectives: Investigating the peripheral neuropathy prevalence in patients with chemical burn in a Burn Hospital, Shiraz. performing electrodiagnostic (EDX) study for all patients both on tibial and median nerve based on the reference data and in order to rule out polyneuropathy. Examining Motor nerve conduction velocities using standard procedures with concentric needle electrodes among all samples. Defining Peripheral neuropathies scored as mono- or polyneuropathy compared with the number of involved nerves.

Methods: In this cross-sectional study, 59 patients with chemical burns were recruited from those referring to Shiraz Central Burn Hospital. The patients underwent a nerve conducting study besides electromyography in order to evaluate the tibial and median nerves after filling the informed consent. Also, a questionnaire covering the demographic data, the chemical agent responsible for the burn, and some other relevant information was given to each patient. The incidence of peripheral neuropathy and distance was calculated with a $95 \%$ incidence.

Results: Twenty-three patients (38.9\%) had peripheral neuropathy, of whom 19 cases (32.2\%) had mono-neuropathy and 4 cases $(6.78 \%)$ had poly-neuropathy. Axonotmesis was frequently found in patients with mono-neuropathy. The most frequent chemical agent responsible for burn was acid (56.4\%). Hands were the most common site of burn $(n=2235.4 \%)$. We also evaluated the mean of total body burned surface area as $2.24 \pm 1.03 \%(1-9 \%)$.

Conclusion: Based on our results, peripheral neuropathy has a high prevalence in localized chemical burns.

\footnotetext{
* Corresponding Author:

Seyed Ehsan Daneshmand, MD.

Address: Orthopaedic Residency Bone and Joint Reconstruction Research Center, Iran University of Medical Sciences, Tehran, Iran

Phone: +98 (936) 7849264

E-mail: ehsanehsan30@gmail.com
} 


\section{Introduction}

$t$ has indicated that peripheral neuropathy is one of the most frequent disabling neuromuscular sequel of burn incidents $[1,2]$. This frequent condition is associated with thermal, electrical, and chemical injuries. Peripheral neuropathy is not well documented or recognized in burn patients; hence, it is probably frequently missed or overlooked in clinical settings [2]. An association between peripheral neuropathy and burn incidents has been established, which is varied widely [2,3], for example, $2 \%$ to $84 \%$ of burn patients, depending on different methodologies. Helm et al. assessed 66 burn patients and reported neuromuscular problems in $29 \%$ of burn patients [4], while Gabriel et al. reported the prevalence of 5\% (18/370) Moreover, peripheral neuropathy has a serious effect on rehabilitation [5].

On the other hand, there is a large spectrum of chemical burns, which can cause ocular and also cutaneous burns and also have systemic effects that can be caused by absorption and inhalation, which require medical and/or surgical treatments $[6,7]$. Considering the nature of these agents and the type of injuries they cause (for example, the depth of the injury, lung injury, eye damage, etc.), they decrease working time and unfortunately, long-term complications are common [8].

It has been shown that 25,000 and more chemicals are used in some industries, cleaners, agriculture, etc., which many of them can cause burns $[9,10]$. Therefore, chemical burns are expected in household and industrial settings $[9,10]$.

The peripheral neuropathy caused by chemical burns has been addressed [11]. Mononeuritis multiplex has been reported as the most usual type of injury in peripheral neuropathy that is observed in $69 \%$ of burnt patients [3]. The major factors associated with burns leading to peripheral neuropathy are the age of over 20 years, electrical burns, full-thickness burns, and burns affecting more than $20 \%$ of the body surface area [12]. Also, the length of hospitalization stay and the burn severity are correlated with the number of affected nerves [13]. Still, little information is available about the correlation between peripheral neuropathy and burns, especially factors affecting the presence or severity of peripheral neuropathy $[1,4,8]$.
Accordingly, we aimed at investigating the peripheral neuropathy prevalence in patients with chemical burn in a Burn Hospital, Shiraz.

\section{Methods}

\section{Sampling}

In this cross-sectional study, all patients with local chemical burns referring to the Burn Hospital, Shiraz were selected from May 2013 to January 2014. We excluded patients with a positive history of peripheral neuropathy, preexisting neurological problems, including traumatic brain injury or stroke or any other medical conditions, which could lead to neuropathy, such as collagen vascular diseases, dermatomyositis, uremia, or alcohol abuse and history of taking any drug affecting the autonomic nervous system or known neurotoxic drugs. Patients with technical barriers, such as open wounds, casts, or dressings, as well as previous burns, contracture, or loss of skin were also excluded.

Among 62 patients who had local chemical burns one week before including in this study and undergoing electrodiagnostic (EDX) study, three patients were excluded based on the exclusion criteria. The remaining subjects $(\mathrm{N}=59)$ underwent electromyography to evaluate the peripheral nerves. The demographic data, including sex, marital status, the chemical agent responsible for the burn, and the site and percentage of burn were collected. EDX examination, including electromyography and Motor Nerve Conduction Velocity (MNCV) were performed for all patients both on tibial and median nerve based on the reference data and in order to rule out polyneuropathy [22]. The procedures were also performed in other body regions, such as on upper and lower limbs (based on the examiner's clinical findings) using a computer-based system (MEB9102K; Nihon-Kohden, Tokyo, Japan).

Motor nerve conduction velocities were examined using standard procedures with concentric needle electrodes. The pulses with $0.2 \mathrm{~ms}$ duration and the rate of $1 \mathrm{~s}$ at supra-maximal intensity were used in our conduction study.

Peripheral neuropathy is also named demyelinating neuropathy, axonotmesis, and entrapment neuropathy. The considered criteria for demyelinating neuropathy are a marked prolonged terminal latency, which is more than $50 \%$ of the normal control group values, slow Nerve Conduction Velocity (NCV) of more than $40 \%$ below the normal mean and with a normal amplitude of 
Compound Muscle Action Potential (CMAP), abnormal shape of CMAP (multiple phases or prolonged time), and innervated muscles with the same neuropathic features as those described for axonal degeneration. The considered criteria for axonotmesis are a reduction in the amplitude of CMAP (two or more standard deviations below the mean of normal values) but with normal shape and duration, normal NCV, and distal latency or minimal disturbance. Also, denervation potential, such as fibrillation or positive sharp wave, increased amplitude duration of the motor unit potentials, and a reduction in recruitment in the muscle innervated by the affected nerve was also noted. Entrapment neuropathy was defined as the focal slowing in nerve conduction across the site of entrapment by $20 \%$ below the lower limit of the control motor conduction with a reduction of CMAP amplitude by $-2 \mathrm{SD}$ of the normal value. Peripheral neuropathies scored as mono- or polyneuropathy compared with the number of involved nerves.

\section{Statistical analysis}

The descriptive statistics, including frequencies and percentages, were calculated and shown in tables. Data were analyzed using SPSS version 18.

\section{Results}

From the 62 patients' records, all patients met the inclusion criteria, of whom 44 patients $(70.9 \%)$ were male and 18 patients $(29 \%)$ were female with a Mean \pm SD age of $34.50 \pm 18.32(7-59)$ years.
Table 1 presents the demographic data and the distribution of chemical agents that caused burns. The total percentage of body surface area affected by chemical burn is demonstrated in Table 2. The percentage of burn surface area was $1 \%$ to $9 \%$. The distribution of the affected area by chemical burns is presented in Table 3. Hands were injured more frequently than other areas, while genitalia faced the lowest damage.

Based on EDX examinations, 19 patients (32.2\%) had mono-neuropathy and 4 patients $(6.78 \%)$ had poly-neuropathy (other patients did not follow mono- or poly-neuropathy criteria). Type, size, and the locations of affected organs in mono-neuropathy vs poly-neuropathy are provided in Table 4. Axonotmesis was frequently found in patients with mono-neuropathy $(n=13,68 \%)$. The number of subjects with axonotmesis was significantly higher than those with demyelinating neuropathies considering the patients with large burns. Acids were the most common cause of mono- and polyneuropathy.

The most frequent chemical agent causing burn was acid (56.4\%), followed by herbal drugs (8\%), alkali $(4.8 \%)$, and rubber $(4.8 \%)$. Hands were the most common site of burn $(n=22,35.4 \%)$, followed by feet $(n=18$, $29 \%)$ and face $(n=14,22,5 \%)$. There were no significant gender differences regarding the burn sites. The mean burned Total Body Surface Area (TBSA) was $2.24 \pm 1.03 \%$ (1-9\%). Injuries involved less than $9 \%$ of TBSA were found in 61 patients (98.4\%) and only one patient had burn injuries of $9 \%$ TBSA.

Table 1. Demographic data of the patients and the chemicals causing burn

\begin{tabular}{|c|c|c|c|c|c|}
\hline Variables & Male & Female & Single & Married & Total \\
\hline Acid & $\mathrm{N}=27$ & $\mathrm{~N}=8$ & $N=10$ & $\mathrm{~N}=25$ & $56.4 \%(\mathrm{~N}=35)$ \\
\hline Alkali & $N=3$ & $\mathrm{~N}=0$ & $\mathrm{~N}=1$ & $\mathrm{~N}=2$ & $4.8 \%(\mathrm{~N}=3)$ \\
\hline Herbal drug & $\mathrm{N}=2$ & $N=3$ & $\mathrm{~N}=0$ & $N=5$ & $8.0 \%(\mathrm{~N}=5)$ \\
\hline Paraffin & $N=1$ & $\mathrm{~N}=1$ & $\mathrm{~N}=1$ & $\mathrm{~N}=1$ & $3.2 \%(\mathrm{~N}=2)$ \\
\hline Rubber & $\mathrm{N}=3$ & $\mathrm{~N}=0$ & $\mathrm{~N}=0$ & $N=3$ & $4.8 \%(N=3)$ \\
\hline Hydrocarbon & $\mathrm{N}=1$ & $\mathrm{~N}=0$ & $\mathrm{~N}=1$ & $\mathrm{~N}=0$ & $1.6 \%(\mathrm{~N}=1)$ \\
\hline Toilet material & $\mathrm{N}=0$ & $\mathrm{~N}=2$ & $\mathrm{~N}=0$ & $\mathrm{~N}=2$ & $3.2 \%(\mathrm{~N}=2)$ \\
\hline Unknown Chemicals & $\mathrm{N}=7$ & $\mathrm{~N}=4$ & $N=3$ & $\mathrm{~N}=8$ & $17.7 \%(\mathrm{~N}=11)$ \\
\hline \multirow{3}{*}{ Total } & $70.9 \%$ & $29.0 \%$ & & & \\
\hline & & & $25.8 \%(\mathrm{~N}=16)$ & $74.1 \%(\mathrm{~N}=46)$ & $\mathrm{N}=62$ \\
\hline & $(\mathrm{N}=44)$ & $(\mathrm{N}=18)$ & & & \\
\hline
\end{tabular}


Table 2. Percentage of burned body surface area by chemicals

\begin{tabular}{cccccc}
\hline Percentage of Total Body Surface Area (TBSA) & $\mathbf{1 \%}$ & $\mathbf{2 \%}$ & $\mathbf{3} \%$ & $\mathbf{4 \%}$ & $\mathbf{9 \%}$ \\
\hline Acid & $\mathrm{N}=5$ & $\mathrm{~N}=24$ & $\mathrm{~N}=2$ & $\mathrm{~N}=3$ & $\mathrm{~N}=1$ \\
\hline Alkali & $\mathrm{N}=0$ & $\mathrm{~N}=2$ & $\mathrm{~N}=0$ & $\mathrm{~N}=1$ & $\mathrm{~N}=0$ \\
\hline Herbal drug & $\mathrm{N}=1$ & $\mathrm{~N}=3$ & $\mathrm{~N}=0$ & $\mathrm{~N}=1$ & $\mathrm{~N}=0$ \\
\hline Paraffin & $\mathrm{N}=0$ & $\mathrm{~N}=1$ & $\mathrm{~N}=1$ & $\mathrm{~N}=0$ & $\mathrm{~N}=0$ \\
\hline Rubber & $\mathrm{N}=0$ & $\mathrm{~N}=0$ & $\mathrm{~N}=2$ & $\mathrm{~N}=1$ & $\mathrm{~N}=0$ \\
\hline Hydrocarbon & $\mathrm{N}=0$ & $\mathrm{~N}=1$ & $\mathrm{~N}=0$ & $\mathrm{~N}=0$ & $\mathrm{~N}=0$ \\
\hline Toilet material & $\mathrm{N}=1$ & $\mathrm{~N}=1$ & $\mathrm{~N}=0$ & $\mathrm{~N}=0$ & $\mathrm{~N}=0$ \\
\hline Unknown chemicals & $\mathrm{N}=2$ & $\mathrm{~N}=9$ & $\mathrm{~N}=0$ & $\mathrm{~N}=0$ \\
\hline Total & $14.5 \%(\mathrm{~N}=9)$ & $66.1 \%(\mathrm{~N}=41)$ & $8.0 \%(\mathrm{~N}=5)$ & $9.6 \%(\mathrm{~N}=6)$ & $1.6 \%(\mathrm{~N}=1)$ \\
\hline $\mathrm{N}$ : Number of patients. & & & & Orthopedic Science
\end{tabular}

Axonotmesis was found in 14 patients (23.7\%), demyelination in 3 patients $(5.0 \%)$, and entrapment neuropathy in 2 patients $(3.4 \%)$. The frequency of neuropathy types did not differ notably between the groups of patients with different causes of burn.

\section{Discussion}

Nowadays, chemical burns have become a major risk factor in daily life $[6,8]$. More than 25000 chemical agents are using in industry, agriculture, household cleaners, etc. A large number of these chemicals can cause burn [9, 10]. Although these factors are responsible for only $3 \%$ of burns, their attributed morbidity, and mortality, have been highly reported $(55 \%$ of cases had been survived by surgical interventions, and $30 \%$ cases led to death) [14]. Despite some similarities between chemical burns and other types of burns (thermal, electrical, etc.), chemical burns have different consequences due to their systemic absorption and various mechanisms of action [15].

Several studies have reported peripheral nervous system dysfunction as a result of the systemic response to chemical agents $[1-3,5]$. On the other hand, as reported in a large number of studies, peripheral neuropathy caused by burning, especially in electrical burns was defined as the biggest dilemma $[6,8,11]$.

Table 3. The affected area by chemical agents

\begin{tabular}{|c|c|c|c|c|c|c|c|}
\hline Variables & Foot & Hand & Chest & Face & Neck & Back & Genitalia \\
\hline Acid & $N=7$ & $\mathrm{~N}=14$ & $\mathrm{~N}=2$ & $\mathrm{~N}=8$ & $\mathrm{~N}=2$ & $\mathrm{~N}=2$ & $\mathrm{~N}=0$ \\
\hline Alkali & $\mathrm{N}=0$ & $\mathrm{~N}=3$ & $\mathrm{~N}=0$ & $\mathrm{~N}=0$ & $\mathrm{~N}=0$ & $\mathrm{~N}=0$ & $\mathrm{~N}=0$ \\
\hline Herbal drug & $\mathrm{N}=4$ & $\mathrm{~N}=1$ & $\mathrm{~N}=0$ & $\mathrm{~N}=0$ & $\mathrm{~N}=0$ & $\mathrm{~N}=0$ & $\mathrm{~N}=0$ \\
\hline Paraffin & $\mathrm{N}=1$ & $\mathrm{~N}=1$ & $\mathrm{~N}=0$ & $\mathrm{~N}=0$ & $\mathrm{~N}=0$ & $\mathrm{~N}=0$ & $\mathrm{~N}=0$ \\
\hline Rubber & $\mathrm{N}=0$ & $\mathrm{~N}=2$ & $\mathrm{~N}=0$ & $\mathrm{~N}=1$ & $\mathrm{~N}=0$ & $\mathrm{~N}=0$ & $\mathrm{~N}=0$ \\
\hline Hydrocarbon & $\mathrm{N}=0$ & $\mathrm{~N}=1$ & $\mathrm{~N}=0$ & $\mathrm{~N}=0$ & $\mathrm{~N}=0$ & $\mathrm{~N}=0$ & $\mathrm{~N}=0$ \\
\hline Toilet material & $\mathrm{N}=0$ & $\mathrm{~N}=1$ & $\mathrm{~N}=0$ & $\mathrm{~N}=2$ & $\mathrm{~N}=0$ & $\mathrm{~N}=0$ & $\mathrm{~N}=0$ \\
\hline Unknown chemical & $\mathrm{N}=6$ & $\mathrm{~N}=1$ & $\mathrm{~N}=1$ & $\mathrm{~N}=3$ & $\mathrm{~N}=0$ & $\mathrm{~N}=0$ & $\mathrm{~N}=1$ \\
\hline Total & $29.0 \%(\mathrm{~N}=18)$ & $35.4 \%(N=22)$ & $4.8 \%(\mathrm{~N}=3)$ & $22.5 \%(\mathrm{~N}=14)$ & $3.2 \%(\mathrm{~N}=2)$ & $3.2 \%(\mathrm{~N}=2)$ & $1.6 \%(\mathrm{~N}=1)$ \\
\hline
\end{tabular}


Table 4. Type, Size, and the locations of affected organs in mono-neuropathy vs poly-neuropathy

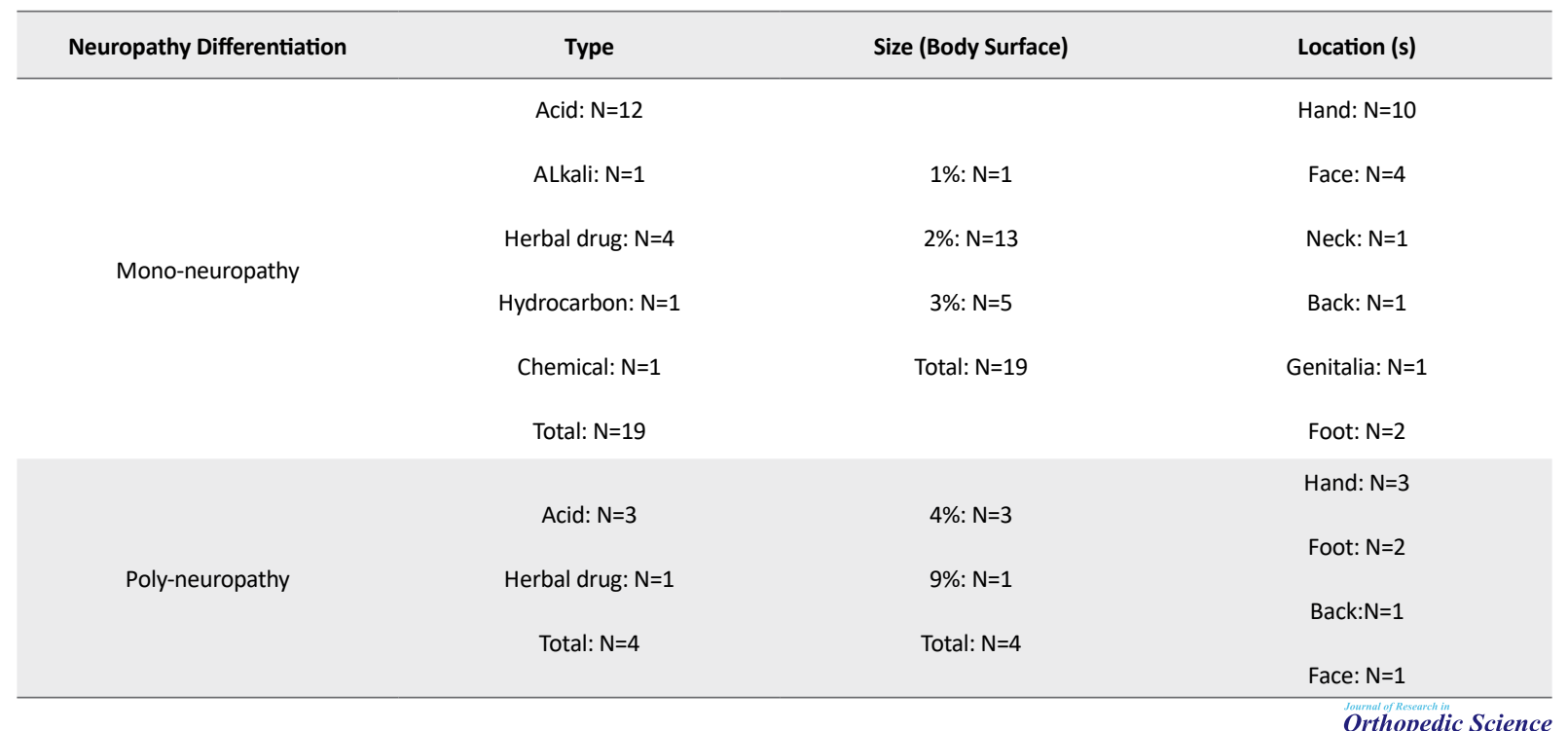

In thermal and electrical burns, the release of systemic inflammatory factors into bloodstream can lead to neuropathy [3]. However, in chemical burns, absorption of chemical agents can be another cause for neuropathy [16]. In thermal injuries, peripheral neuropathy was reported following major burns (TBSA $>20 \%$ ), while in our study, patients even with low TBSA percentage had experienced peripheral neuropathy [17].

Peripheral neuropathy is known as a major challenge in electrical burns, and in North America, the electrical burn prevalence has been estimated to be 20000 subjects annually [18]. In the Nigeria Burn Center, $2.8 \%$ of total burns from 1995 to 2004 were attributed to electrical burn [19]. Similarly, in Shiraz Burn Center, 4.7\% of total burn complaints were caused by electrical injuries, which were associated with peripheral neuropathy.

In our study, a high prevalence of neuropathy (38.9\%) in chemical burn patients even with a low percentage of TBSA was reported. The prevalence is almost higher than those found in other studies on electrical and thermal burn patients. As mentioned earlier, the electrical burn has been presented as the main risk factor for peripheral neuropathy. However, given the high frequency of peripheral neuropathy in our patients with chemical burns compared with its frequency in patients with electrical burns studied in several investigations, chemical burn patients can be considered to have a higher risk for developing peripheral neuropathy.

In addition to inflammatory mediators and systemic reactions associated with all burn mechanisms, systemic absorption of chemical agents responsible for local chem- ical burns can play a role in peripheral neuropathy. Certainly, a number of biochemical and histological studies with a larger study population and conducted in a multicenter manner are needed to provide more solid evidence to this claim. All 23 patients with neuropathy in our study group were female, which could indicate that gender plays a role in peripheral neuropathy development.

Electrophysiological studies have detected peripheral neuropathy within a week after burns [20]. Some researchers believe that this can be caused by the acute phase reactants, which are released in response to burn because they are subsided over time [20]. However, the long-term involvements in the motor nervous system have been discussed by Haberal et al. They confirmed that persistent peripheral nerve pathologies are more frequent in electric burn patients [21].

\section{Ethical Considerations}

\section{Compliance with ethical guidelines}

All ethical principles are considered in this article. The participants were informed of the purpose of the research and its implementation stages. They were also assured about the confidentiality of their information and were free to leave the study whenever they wished, and if desired, the research results would be available to them. A written consent has been obtained from the subjects. principles of the Helsinki Convention was also observed. 


\section{Funding}

This research did not receive any grant from funding agencies in the public, commercial, or non-profit sectors.

\section{Authors' contributions}

Methodology: Seyed Ehsan Daneshmand; Investigation: Ladan Masoumi; Writing - original draft: Ladan Masoumi; Sharareh Roshanzamir; Writing - review \& editing: Seyed Ehsan Daneshmand; Funding acquisition : Seyed Ehsan Daneshmand; Resources: Seyed Ehsan Daneshmand; Supervision: Sharareh Roshanzamir.

\section{Conflict of interest}

The authors declared no conflict of interest.

\section{Acknowledgments}

Special Thanks to Dr Sharareh Roshanzamir from Shiraz University of medical sciences for her fantastic ideas and helps to organise this thesis and many thanks to whom contributed in this article.

\section{References:}

[1] Barrell K, Smith AG. Peripheral neuropathy. Med Clin North Am. 2019; 103(2):383-97. [DOI:10.1016/j.mcna.2018.10.006] [PMID]

[2] Tu Y, Lineaweaver WC, Zheng X, Chen Z, Mullins F, Zhang F. Burn-related peripheral neuropathy: A systematic review. Burns. 2017; 43(4):693-9. [DOI:10.1016/j.burns.2016.08.003] [PMID]

[3] Strong AL, Agarwal S, Cederna PS, Levi B. Peripheral neuropathy and nerve compression syndromes in burns. Clin Plast Surg. 2017; 44(4):793-803. [DOI:10.1016/j. cps.2017.05.010] [PMID] [PMCID]

[4] Helm P, Pandian G, Heck E. Neuromuscular problems in the burn patient: Cause and prevention. Arch Phys Med Rehabil. 1985; 66(7):451-3. [PMID]

[5] Gabriel G, Thomas PK, King RH, Stolinski C, Breathnach AS. Peripheral nerve intramembranous particle density and distribution in chronic streptozotocin-induced diabetes in rats. Acta Neuropathol. 1986; 72(1):62-8. [DOI:10.1007/ BF00687948] [PMID]

[6] Church D, Elsayed S, Reid O, Winston B, Lindsay R. Burn wound infections. Clin Microbiol Rev. 2006; 19(2):403-34. [DOI:10.1128/CMR.19.2.403-434.2006] [PMID] [PMCID]

[7] Eslani M, Baradaran-Rafii A, Movahedan A, Djalilian AR. The ocular surface chemical burns. J Ophthalmol. 2014; 2014:196827. [DOI:10.1155/2014/196827] [PMID] [PMCID]
[8] Palao R, Monge I, Ruiz M, Barret JP. Chemical burns: Pathophysiology and treatment. Burns. 2010; 36(3):295-304 [DOI:10.1016/j.burns.2009.07.009] [PMID]

[9] Sawhney CP, Kaushish R. Acid and alkali burns: Considerations in man-agement. Burns. 1989; 15(2):132-4. [DOI:10.1016/0305-4179(89)90146-0]

[10] Monafo W, Bessey P. Total burn care. Herndon DN ed. $4^{\text {th }}$ edition. London, United Kingdom: WB Saunders; 2012. https://www.elsevier.com/books/total-burncare/9780323476614

[11] Friedstat J, Brown DA, Levi B. Chemical, electrical, and radiation injuries. Clin Plast Surg. 2017; 44(3):657-69. [DOI:10.1016/j.cps.2017.02.021] [PMID] [PMCID]

[12] Klifto KM, Dellon AL, Hultman CS. Prevalence and associated predictors for patients developing chronic neuropathic pain following burns. Burns Trauma. 2020; 8:tkaa011. [DOI:10.1093/burnst/tkaa011] [PMID] [PMCID]

[13] Agbenorku P, Akpaloo J, Yalley D, Appiah A. A new era in the management of burns trauma in Kumasi, Ghana. Ann Burns Fire Disasters. 2010; 23(2):59-66. [PMID] [PMCID]

[14] Olaitan PB, Jiburum BC. Analysis of burn mortality in a burns centre. Ann Burns Fire Disasters. 2006; 19(2):59-62 [PMID] [PMCID]

[15] Tiwari VK. Burn wound: How it differs from other wounds? Indian J Plast Surg. 2012; 45(2):364-73. [DOI:10.4103/09700358.101319] [PMID] [PMCID]

[16] Anderson SE, Meade BJ. Potential health effects associated with dermal ex-posure to occupational chemicals. Environ Health Insights. 2014; 8(suppl 1):51-62. [DOI:10.4137/EHI S15258] [PMID] [PMCID]

[17] Tamam Y, Tamam C, Tamam B, Ustundag M, Orak M, Tasdemir N. Peripheral neuropathy after burn injury. Eur Rev Med Pharmacol Sci. 2013; 17(suppl 1):107-11. [PMID]

[18] Singerman J, Gomez M, Fish JS. Long-term sequelae of lowvoltage electri-cal injury. J Burn Care Res. 2008; 29(5):773-7. [DOI:10.1097/BCR.0b013e318184815d] [PMID]

[19] Opara KO, Chukwuanukwu TO, Ogbonnaya IS, Nwadinigwe CU. Pattern of severe electrical injuries in a Nigerian regional burn centre. Niger J Clin Pract. 2006; 9(2):124-7. [PMID]

[20] Margherita AJ, Robinson LR, Heimbach DM, Fishfader VL, Schneider VA, Jones D. Burn-associated peripheral polyneuropathy: A search for causative fac-tors. Am J Phys Med Rehabil. 1995; 74(1):28-32. [DOI:10.1097/00002060-19950100000005] [PMID]

[21] Haberal MA, Gürer S, Akman N, Başöze O. Persistent peripheral nerve pa-thologies in patients with electric burns. J Burn Care Rehabil. 1996; 17(2):147-9. [DOI:10.1097/00004630-199603000-00008] [PMID] 